DIGITALCOMMONS

@WAYNESTATE-
Michigan Journal of Counseling:

Research, Theory and Practice

Volume 30 | Issue 2

Article 5

$8-1-2002$

\title{
Cognitive Restructuring: A Counseling Approach For Improving The ADHD Child's Self-Concept
}

Paul Lavin

Norbel School

Follow this and additional works at: https://digitalcommons.wayne.edu/mijoc

\section{Recommended Citation}

Lavin, P. (2002). Cognitive Restructuring: A Counseling Approach For Improving The ADHD Child's Self-Concept, Dimensions of Counseling, 30(2), 22-27. doi: $10.22237 / \mathrm{mijoc} / 1028160240$

This In the Field is brought to you for free and open access by the Open Access Journals at DigitalCommons@WayneState. It has been accepted for inclusion in Michigan Journal of Counseling: Research, Theory and Practice by an authorized editor of DigitalCommons@WayneState. 


\section{In The Field}

\section{Cognitive Restructuring: A Counseling Approach For Improving The ADHD Child's Self-Concept}

\section{Paul Lavin, Ph.D.}

Paul Lavin, Ph.D. is a consultant with the Norbel School, a

facility in Maryland for ADHD and learning disabled youngsters.

Correspondence regarding this article can be sent to: Paul Lavin,

Ph.D., 9 Park Drive, Catonsuille, MD 21228. hildren diagnosed with Attention Deficit

Hyperactivity Disorder (ADHD) are characteristically over-active, inattentive, and impulsive (American Psychiatric Association,1994). Such symptomology can be significantly problematic because it interferes with the child's capability to learn in school and to establish viable relationships with peers and persons in authority (Erk, 2000). Over time, the chronic and repeatedly negative feedback from others can severely erode the child's confidence. As a result, ADHD children, unless identified early and provided with appropriate services, often develop a poor self-concept (Gresham \& Elliott, 1984; McConnell \& Odom, 1986). Thus, they perceive themselves as being inadequate in comparison to their age mates (Cotugno, 1995; Erk, 1995,1997). ADHD children, even though they may act out and become oppositional, engage in such behavior because they view themselves as being powerless, thinking that they are incapable of controlling themselves and those events affecting their lives (Bandura, 1977; Weiner, 1979). It is not surprising, therefore, that they develop an "external locus of control," believing that luck, outside events, or other people are responsible for what happens to them (Dweck, 1975; Lavin, 1989; Linn \& Hodge, 1982; Rosenbaum \& Baker, 1984). ADHD children who take medication can be particularly prone to such kind of thinking. Often, they will attribute their success or failure to whether they did or did not take their pills that day (Lavin, 1989; Whalen \& Henker, 1976). This author recalls one youngster who referred to Ritalin as his "good boy pill;" while another child referred to it as "my dope" (Lavin, 1989). Obviously, children who think in this vein are unlikely to take responsibility for their actions. As a result, they tend to 
keep engaging in dysfunctional behavior, leading to continued failure and even more negative feedback from others (Goldstein \& Goldstein, 1990).

In order for the ADHD child to develop a healthy self-concept, a change in his or her views about self, life, and other people must occur. The development of an "internal locus of control," learning to take responsibility for one's actions, is considered to be one of the critical components necessary for such change to occur (Byrd \& Byrd, 1986; Crandall \& Katkovsky, 1965; Dweck, 1975; Gagne, 1975; Lavin, 1989; McGuiness, 1985; Reid \& Borkowski, 1987; Seligman, 1975).

Fostering the development of an "internal locus of control" can be achieved by teaching the ADHD child to engage in more productive thinking by emphasizing positive rather than negative self-attributions (Dweck, 1975; Lavin, 1989; Reid \& Borkowski, 1987). Positive, productive thoughts can help to modify the child"s negative affect (anxiety; depression; frustration) and those impulsive, over-reactions that often follow (Henker, Whalen, \& Hinshaw, 1980). Moreover, by learning to generate such thoughts, the youngster can not only gain better emotional control, but he or she can become more capable of weighing choices and planning and anticipating the consequences of his or her actions (Dweck, 1975; Lavin, 1989; Licht, Kistner, Ozkaragoz, Shapiro, \& Clausen, 1985; Reid \& Borkowski, 1987). While learning and acquiring this skill is not an easy task, with motivation, and practice, it will become a "cognitive habit" so to speak. This, in essence, helps the child to change from being a powerless victim, to one who can achieve successfully, despite ADHD symptomology. By directly teaching ADHD children to think more productively, a major gain can occur in improving their self-confidence and in their willingness to assume responsibility for making good choices. Hence, the development of an "internal locus of control" is not only fostered but can then become an integral part of the child's personality.

It should be kept in mind that ADHD children have a different mind set than that of ordinary youngsters. Many of them have been told that ADHD is genetically or biochemically based. While there is certainly a body of current evidence to support this (Erk, 2000), it can also lead ADHD children to believe that there is little, or nothing that they can do to control what happens to them. As noted earlier, for those children who take medication, success or failure can be attributed to ingesting or not ingesting "the pill." The child might insist that without the pill to correct his or her "chemical imbalance," selfcontrol would be virtually impossible. It is this mind set which must be challenged if the child is to learn that, despite ADHD, he or she can take positive steps in controlling attention, impulse, and behavior. In other words, ADHD children must learn that even with their so called "handicapping condition," they can perform successfully if they are willing to make the effort to do so.

\section{The First Step: Establishing Rapport}

In order to set the foundation for cognitive restructuring to occur, the counselor must first be able to empathize with the ADHD child (Erk, 2000; Lambert \& CattaniThompson, 1996). Clearly communicating to the child that ADHD was acquired by factors beyond his control, not a condition brought about by his own choosing, can help. Moreover, letting the child know that being diagnosed with ADHD would be frustrating for anyone can be beneficial. themselves and

those events iffectina their lives
After all, the majority of youngsters are not
this affliction. As a result, they appear to cursed with this affliction. As a result, they appear to
have a much easier time learning in school and getting along with teachers, peers, and other adults.

By empathizing with the ADHD child, the counselor achieves two purposes. First, it enables him or her to build rapport with the youngster. Second, this makes it more likely that the child will be receptive to and integrate that which the counselor communicates. In order to demonstrate empathy, the counselor might state something like the following:

You are right about ADHD being a problem that causes difficulty for you. It is frustrating because you didn't choose to have ADHD. It seems that people are always acting like it's your fault because you have trouble with self-control. The real reason why you have trouble controlling yourself is that you have more energy than most people. This is something that you were born with, not something that you intentionally caused to happen. So when you fidget, become distracted, or react quickly without thinking, it is because this uncontrollable energy is influencing you to behave this way. Most people don't understand this and when they criticize you it hurts and is irritating because you believe that it's unfair to be blamed for something that you can't help. 
By communicating empathy in this manner, the ADHD child is more likely to perceive the counselor as a trustworthy advocate; someone who is not only understanding but who also may be able to help him or her with self-control problems. In order to achieve the latter, the following might be added to the preceding. This will enable the youngster to see that he or she can learn to gain control and to manage their seemingly unbound less energy:

As I just indicated, you have more energy than most people. Actually, having lots of energy is a good thing. If you use this energy properly, you could achieve much more than those people who are less energetic than yourself. You might think of your body as an automobile and your brain as the motor which runs and drives it. Your body contains this large reservoir of gasoline or energy which powers your automobile. The trick for you is to learn how to wisely use your "high test" gasoline so that your automobile runs smoothly and efficiently.

As you know, every automobile has an accelerator, a peddle that when we push down on it, regulates the amount of gas that enters the motor. This is what makes it go faster or slower. If we push the peddle too hard, too much gas causes the automobile to go out of control. If we fail to push the peddle hard enough, then the automobile won't move or it will go too slowly.

Going back to what I said earlier, the trick for you is to learn to regulate your "high powered" energy so that you can use it to be successful at home and school. You might think of your brain as being the accelerator that runs your body. If you control your brain, or what you think, than you could make sure that your automobile always goes at the right speed, not too fast and not too slow. What do you think about what I'm saying?
At this point, the counselor can then affirm whether the child's perception about what has been conveyed is correct or whether further explanation is needed. Once the preceding is completed, then the counselor can move forward in instructing the ADHD child on how to apply cognitive restructuring so that he or she can gain better self-control.

Keep in mind that your brain is the accelerator that controls your behavior. If you think good thoughts, then you will feel happier and make better choices. If you think bad thoughts, then you will be frustrated and behave foolishly and get yourself into trouble. For example, suppose that you believe this: "I have ADHD. Therefore, I am a stupid person." How do you think that you are going to feel? (Pause and let the child respond or continue.) That's right! You would feel "dumb" and inadequate in comparison to your classmates. And if you believe that you are dumb, how will you behave?

(Pause and let the child respond.) That's correct. You're not going to try to do the work and you'll be uncooperative when the teacher tries to make you complete it. In fact, some children even argue with the teacher or act up in goofy ways so that they can avoid doing the assignments. What do you think about that?

Once more, the counselor concludes with a question in order to obtain the child's input so that any errors in perception can be corrected.

\section{The Second Step: Cognitive Restructuring}

Following this introduction, the counselor is then ready to begin working with the ADHD child keeping two objectives in mind. First, those misperceptions which are particularly common to ADHD children need to be specifically identified. Second, specific productive thoughts to replace these must be generated. Those counter productive thoughts $(\mathrm{CP})$, which this author has found to be particularly prevalent with ADHD youngsters, and their productive $(\mathrm{P})$ replacements are as follows: 


\section{Counterproductive Thoughts Counselor Positive Replacements}

1 I have ADHD. This means that I am dumb and stupid in comparison to my classmates.

2 Having ADHD is unfair. It's not my fault that I have this problem. I didn't choose to be this way. Peers and adults should understand this and stop criticizing and blaming me.
Because you have ADHD, doesn't mean that you are dumb or stupid. In fact, ADHD children are just as smart as most of their classmates. Having ADHD means that you have more energy than most people. You have trouble controlling this energy. That's the problem. You have plenty of "brain power." However, your only problem is learning how to use it properly.

You are right that you didn't choose to have ADHD. Of course, you believe that having ADHD is unfair and that people should "get off your case" about it. Unfortunately, life itself is unfair. Almost everybody has a problem. (Give an example: Louis has trouble throwing and catching a ball. The other boys make fun of him because of this. However, he can't help it.) You think that having lots of energy is unfair. However, if you learn to control this energy and use it wisely, then you could actually do better than most people. This is something you could fix if you are willing to make the effort.
3 I have a "chemical imbalance." Because of this, I am incapable of controlling myself. That's why I take pills. Without pills, there is nothing I can do about my behavior.
Pills can help to calm you by slowing your motor down. However, it is using your brain and learning to think correctly that is most important in helping you to gain control of yourself. When you learn to control yourself, then you will feel proud because you made the right choice and behaved appropriately. You are responsible for this, not the "pill."
4 When something is difficult for me, I shouldn't have to do it. After all, I have ADHD and I can't help getting frustrated when hard tasks are assigned to me.

5 Because I have ADHD, other kids tease and make fun of me. They call me "hyper boy" and other bad names. People in authority should stop the teasing and severely punish them for hurting my feelings. They should always protect me.
While it's true that having ADHD is frustrating, it doesn't mean that you can't overcome the frustration and complete the task. The chances are that your teachers and parents give you tasks that you are actually capable of completing, if you calm yourself and make the effort. In fact, by overcoming your frustration and completing the assignment, you will be demonstrating good self-control. This will make you proud because you will be doing this using your own brain power in controlling your energy.
You are right that other kids say mean things. Some may even try to hurt your feelings by making fun of you. Teachers can punish them when they are caught teasing you. However, this won't solve the problem. Rather, how you react to the teasing and what you do to correct your behavior is what will fix this over time. (Instructions can be provided here.) For example, some kids will call you "hyper boy" because they know that this hurts your feelings and then you will lose your temper and get into trouble. They even laugh when this happens. If you would learn to ignore and not react to them, they would stop their little game of having fun at your expense. Keep in mind that you will have to follow this plan for a long time before they change how they react to you. Remember, you have a certain reputation with them. They expect that if they keep it up, you'll over-react. So it won't be easy to change them. With effort, you could do it and succeed, however. Imagine how proud you will feel, when you beat them at their own game because you controlled yourself. 
Although the preceding applies specifically to ADHD children, there are other negative views that young people hold which interfere with their capacity to function successfully. This author has identified a number of "twisted" thoughts, which if replaced with "straight" thinking, can also help ADHD children to gain better control of their emotions and behavior (Lavin, 1991a).

\section{The Case of George}

George was a 10 year old boy who had been diagnosed with ADHD by his pediatrician. While George was taking Ritalin for this disorder, he continued to have problems at home and school. George was inattentive, impulsive, and had become increasingly more irritable with his teachers and parents. By the time he was referred to the counselor, George had become markedly oppositional, frequently refusing to cooperate or follow instructions.

The use of a behavior modification program in conjunction with cognitive restructuring can be particularly efficacious in teaching the ADHD child to attend, to control impulse, and to take responsibility for making better choices. Behavior modification in combination with other treatment modalities has been highly recommended by researchers and practitioners who work with the ADHD population (Barkley, 1990; Byrd \& Byrd, 1986; Gomez \& Cole, 1991; Lavin, 1989; Lavin, 1991b; McGuiness, 1985). Using a behavioral program which facilitates communication between the teachers and parents on a daily basis can be particularly effective in teaching ADHD youngsters to develop an "internal locus of control" (Lavin, Gold, \& Dellarose, 2000).

After conferring with his parents, it was decided that a behavior modification system, requiring George to earn points for privileges, would be set up and implemented. Of course, George rebelled against this, claiming that his parents had an obligation to provide him not only with the necessities of life but the "luxuries" as well. George, during the course of counseling, stated the following which was indicative of his thinking at that time:

\section{Counseling is stupid. It can't help me with my problems.}

2. I shouldn't have to buy my life (pay points for privileges). My parents always gave me privileges before I came here. They have no right to keep them from me now.

3. You (the counselor) are mean and against me. It's your fault that my parents are taking away what they used to give me for free.
As a result of these faulty views, George became markedly frustrated and refused to cooperate with the program. He was convinced that if he remained adamant, his parents would eventually reinstate his privileges as they had done in the past. During the sessions, in which both George and the parents participated, the counselor focused on George's counter productive beliefs and how these were only contributing to his ongoing frustration. Specifically, the following was pointed out to George:

1. The purpose of the point system was to help, not to hurt George. It was designed to assist him in gaining better self-control and to enable him to get along better with his parents. They were increasingly becoming more frustrated themselves because they could not help him. Moreover, it was pointed out that George was right that behavior modification could not, all by itself, fix his problems. He must make the choice to cooperate if the system was to be of benefit to him. It was also stipulated that if George demonstrated that he could perform successfully, the system would be removed. The decision was up to him.

2. George was not being required "to buy his life." His parents were obliged to provide him with nutritious food, medical attention, a clean place to live, a public school education, and appropriate clothing. These were necessities that never had to be purchased. However, luxury items such as preferred foods, video games, television, movies, and so forth were extras that had to be purchased. When his parents provided these for free and he was not cooperating, this only caused them to become resentful and critical of George. They felt that George was unappreciative, and they would call him a "spoiled brat" because they were frustrated with his errant behavior. This only led to George becoming more disappointed with himself, more uncooperative, and more spiteful in his interactions with them. Nobody was benefiting from the previous "free" privileges and this needed to be corrected.

3. The counselor was "hired" by the parents because George was doing poorly at home and school. The behavioral evidence confirming this was presented. The counselor's purpose, therefore, was to help George and his family. George, the school, and his parents were all unhappy. It made no sense to go on like this. In fact, the sooner George cooperated with his parents and the counselor, the faster that the sessions could be terminated. 
Although it took approximately five weekly counseling sessions, George finally decided that cooperation was the best solution to the problem. At the conclusion of our sessions, his faulty thinking had changed so much that, despite his marked improvement, he wanted to keep the point system in operation. George concluded, "It's not my parents who control my life. It's me. We get along much better now." George, in essence, was now gaining insight and beginning to develop an "internal locus of control." As noted earlier, this is the most important ingredient leading to long lasting success. Needless to say, a well designed and implemented behavior modification system was instrumental in helping to bring these changes about as well.

\section{Conclusions}

In conclusion, cognitive restructuring can be a valuable counseling tool in helping the ADHD child to improve his or her self-concept. Altering the child's faulty views about ADHD and his capability to gain better self-control can go a long way in empowering him to assume responsibility for his actions. An ADHD child who learns to think productively is more likely to acquire an "internal locus of control." As indicated previously, children with such an orientation perform more successfully at home and school. Cognitive restructuring, particularily in conjunction with a behavior modification program, is designed to achieve this objective. It fosters changes in the child's thinking so that he or she can control stress inducing emotions, and curb his or her tendency to act impulsively in response to these. In other words, it enables the child to think before acting by carefully weighing the pros and cons of his or her behavior. By helping the ADHD youngster to modify his or her counter productive views, the foundation for sustained progress can be fostered. It is productive thinking which will enable the child to continue to succeed long after counseling has been terminated.

\section{References}

American Psychiatric Association. (1994). Diagnostic and statistical manual of mental disorders (4th ed.). Washington, DC: Author.

Bandura, A. (1977). Social learning theory. Englewood, Cliffs, NJ: PrenticeHall.

Barkley, R. (1990). Attention deficit hyperactivity disorder: A handbook for diagnosis and treatment. New York: Guilford.

Byrd, D.P., \& Byrd, K.E. (1986). Drugs, academic achievement and hyperactive children. The School Counselor, 23, 323-331.

Cotugno, A.L. (1995). Personality attributes of attention deficit hyperactivity disorder (ADHD) using the Rorschach ink blot test. Journal of Clinical Psychology, 51, 554-561.

Crandall, V., \& Katkovski, W. (1965). Children's beliefs in their own control of reinforcements in intellectual-academic situations. Child Development, 36, 90-109.
Dweck, C.S. (1975). The role of expectations and attributions in the alleviation of learned helplessness. Journal of Personality and Social Psychology, 31, 674-685.

Erk, R.R. (2000). Five frameworks for increasing understanding and effective treatment of attention-deficit / hyperactivity disorder: Predominately inattentive type. Journal of Counseling $\mathcal{E}$ Development, 78, 389-399.

Erk, R.R. (1995). The conundrum of attention deficit disorder. Journal of Mental Health Counseling, 17, 131-145.

Erk, R.R. (1997). Multidimensional treatment of attention deficit disorder: A family oriented approach. Journal of Mental Health Counseling, 19, 3-22.

Gagne, E. (1975). The effects of locus of control and goal setting on persistence at a learning task. Child Study Journal, 5, 193-199.

Goldstein, S., \& Goldstein, M. (1990). Managing attention disorders in children. New York: John Wiley \& Sons.

Gomez, K.M., \& Cole, C.L. (1991). Attention-deficit hyperactivity disorder: A review of treatment alternatives. Elementary School Guidance and Counseling, 26, 106-114.

Gresham, F., \& Elliott, S. (1984). Assessment and classification of children's social skills: A review of methods and issues. School Psychology Review, 13, 292-300.

Henker, B., Walen, C., \& Hinshaw, S. (1980). The attributional context of cognitive motivational strategies. Exceptional Educational Quarterly, 1, 17-30.

Lambert, M.J., \& Cattani-Thompson, K. (1996). Current findings regarding the effectiveness of counseling: Implications for practice. Journal of Counseling \& Development, 74, 601-608.

Lavin,P., Gold, M., \& Dellarose, S. (2000). A home-school partnership program for the ADHD child. East Rockaway, NY: Cummings \& Hathaway.

Lavin, P. (1989). Parenting the overactive child: Alternatives to drug therapy. Lanham, MD: Madison Books.

Lavin, P. (1991a). Teaching kids to think straight. Columbia, MO: Hawthorne.

Lavin, P. (1991b). The counselor as consultant-coordinator for children with attention deficit hyperactivity disorder. Elementary School Guidance and Counseling, 26, 115-120.

Licht, B.G., Kistner, J.A., Ozkaragoz, T., Shapiro, S., \& Clausen, L. (1985). Causal attributions of learning disabled children: Individual differences and their implications for persistence. Journal of Educational Psychology, 77, 208-216.

Linn, R.T., \& Hodge, G.K. (1982). Locus of control in childhood hyperactivity. Journal of Consulting and Clinical Psychology, 50, 592593.

McConnell, S., \& Odom, S. (1986). Sociometrics: Peer referenced measures and the assessment of social competence. In P. Strain, M. Guralnick, \& H. M. Walker (Eds.), Children's social behavior: Development, assessment and modification. New York: Academic Press.

McGuiness, D. (1985). When children don't learn. New York: Basic Books.

Reid, M.K., \& Borkowski, J.G. (1987). Causal attributions of hyperactive children: Implications for teaching strategies and self-control. Journal of Educational Psychology, 79, 206-307.

Rosenbaum, M., \& Baker, E. (1984). Self-control behavior in hyperactive and non-hyperactive children. Journal of Abnormal Child Psychology, $12,303-331$.

Seligman, L. (1975). Helplessness. San Francisco, CA: Freeman.

Walen, C.K., \& Henker, B. (1976). Psychostimulants and children: A review and analysis. Psychological Bulletin, 83, 1113-1130.

Weiner, B. (1979). A theory of motivation for some classroom experiences. Journal of Educational Psychology, 71, 3-25. 